\title{
Technological area experience, experience diversity and innovation
}

\section{Antonio Garzón-Vico, Patrick Gibbons, Peter McNamara \& Jan Rosier}

To cite this article: Antonio Garzón-Vico, Patrick Gibbons, Peter McNamara \& Jan Rosier (2016) Technological area experience, experience diversity and innovation, Technology Analysis \& Strategic Management, 28:9, 1041-1055, DOI: 10.1080/09537325.2016.1181740

To link to this article: https://doi.org/10.1080/09537325.2016.1181740

册 Published online: 05 May 2016.

Submit your article to this journal $\pi$

Џlll Article views: 299

View Crossmark data $₫$ 


\title{
Technological area experience, experience diversity and innovation
}

\author{
Antonio Garzón-Vico ${ }^{\mathrm{a}}$, Patrick Gibbons ${ }^{\mathrm{a}}$, Peter McNamara ${ }^{\mathrm{b}}$ and Jan Rosier ${ }^{\mathrm{a}}$ \\ ${ }^{a}$ Smurfit School of Business, University College Dublin, Dublin, Ireland; ${ }^{b}$ National University of Ireland, Maynooth - \\ School of Business, Maynooth, Kildare ROI, Ireland
}

\begin{abstract}
One conclusion from the knowledge-based view is that firms develop knowledge from experience. This paper examines the conditions under which firms' R\&D experiences might have stronger or weaker effects on innovation capabilities. We posit that any potential benefit depends on the nature of this experience. In particular, we look at how technological area experience and experience diversity affects innovation capabilities. We further propose that, in order to leverage their experience, firms need to consider how the interactions of technological area experience and experience diversity affect performance. To test this model, we draw on a data set of 3034 drug development projects undertaken by 30 large pharmaceutical companies between 1980 and 2008.
\end{abstract}

\section{ARTICLE HISTORY}

Received 14 January 2015

Revised 2 March 2016

Accepted 14 April 2016

\section{KEYWORDS}

Experience diversity; innovation; organisational learning; pharmaceutical; technological area experience

\section{Introduction}

Firm-level knowledge development and its relationship to organisational performance has become one of the dominant themes in the strategic management literature (Grant 1996; Spender 1996). The knowledge-based view (KBV) of the firm holds that firms develop knowledge from experience and stresses the importance for firms to create value from the effective use of experiential knowledge (Grant 1996). Relatively unexplored in the KBV literature is an examination of how different sources/ types of experience explain variation in firms' knowledge development (Macher and Boerner 2012). Still more theoretical and empirical development in this area is needed to expand the knowledgebased theory of the firm.

Studies on innovation have traditionally appealed to factors in either the industry or in the firm. Studies in industrial economy explain innovation performance in the firm by appealing to external and internal factors of the firm (e.g. Souitaris 2002; Vega-Jurado et al. 2008). The present study focuses on factors within the firm. In particular, we explore differences in innovation capabilities within and across firms. These capabilities are narrowly connected to the organisation's ability to develop and transfer knowledge. Innovation capabilities (i.e. rates of project success and failure) are at the core of an organisation's competitive advantage. We develop our theory in the context of the biotech and pharmaceutical industry, in which new product introduction is critical to the survival of firms. Under these circumstances firms in the biotech and pharmaceutical industry are under great pressure to increase their success rate while minimising the cash burn experienced due to failing projects (Garnier 2008).

Working from previous research (Macher and Boerner 2012; Nickerson and Zenger 2004), we assume that in the context of innovation firms create valuable knowledge from their experiences in dealing with 
previous problematic tasks. This understanding of knowledge formation is particularly prominent in the context of the biotech and pharmaceutical industry, given the high levels of uncertainty surrounding the drug development process in this industry (Kaitin and DiMasi 2011). Depending on the characteristics of the problem or task, particular prior experiences are considered to be superior to others (Macher and Boerner 2006). We make a contribution to this area of research by examining the interactive effects that technological area experience and experience diversity have on innovation performance.

We make a number of contributions to the KBV literature. We are the first to study the interactive effect of specific technology area experience and experience diversity on innovation performance. Following other previous works, we understand technology area experience as the level of expertise an organisation has in given domain (Macher and Boerner 2012). Experience diversity refers to the extent to which a firm's technology experience is diversified across different technology areas (Breschi, Lissoni, and Malerba 2003; Gambardella and Torrisi 1998; Xu 2015). In particular, we find that firms can only fully benefit from their technology area experience when combined with experience diversity. Furthermore, we posit that only focusing on technology area experience fails to fully account for the role of experiential learning in innovation. We therefore supplement already existing work on the role of experience in innovation performance (Macher and Boerner 2012) by suggesting the relevant conceptual addition of the interaction between technology area experience and experience diversity to theory. We also employ a more comprehensive understanding of innovation performance and not only consider drug development projects that are successful but also take into account those that are terminated. We therefore supplement the existing literature by adding empirical research on the consequences that experience has on future rates of failure. This is in line with recent work on the importance of failure in the context of knowledge development (Madsen and Desai 2010; Muehlfeld, Rao Sahib, and Van Witteloostuijn 2012; Su and McNamara 2012). We also contribute to the already existing work on drug development which has received substantially less attention than drug discovery (Cockburn and Henderson 2001), even though the costs of development are substantially higher than those of discovery.

\section{Theory and hypotheses}

\subsection{Technology area experience}

Experience in a technological area can lead to developing skills that might be relevant to future-related tasks. The ability to evaluate and develop future projects is largely a function of the level of prior experience relevant to the project in question. For example, prior experience in similar acquisitions can explain the performance of future ones (Haleblian and Finkelstein 1999; McDonald, Westphal, and Graebner 2008), or firms' efficiency in absorbing partner's relevant knowledge in alliances (Reuer, Zollo, and Singh 2002). As they gain experience, firms obtain a better understanding of task requirements which allows them to develop a transactive memory system that helps transfer expertise from one task to another similar task (Argote and Ren 2012; Gino et al. 2010). As a firm increases its experience in one area, it also increases the smoothness and the ease with which it transfers its knowledge to similar tasks. In line with this idea of transactive memory, a firm's technology area experience determines the amount of expertise it has in the area relevant to the project (Schilling et al. 2003).

Technology area experience will determine how the organisation sees a project developing in the future and will ultimately affect the firm's ability to predict possible problems, its confidence regarding the project's potential and its belief in its own ability to complete the project successfully. Firms with higher levels of specialisation in technology area will deepen their ability to resolve complex problems, attain higher levels of insights for future innovation developments (Boh, Evaristo, and Ouderkirk 2014; Lettl, Rost, and von Wartburg 2009) and increase the performance of their R\&D alliances (Ernst, Lichtenthaler, and Vogt 2011). It allows firms to draw on relevant examples that they have experienced in the past, and help them predict the course of action and potential problems for new tasks (Ericsson and Charness 1994). Under these circumstances, firms can draw meaningful comparisons between current tasks and similar previous tasks (Thompson, Gentner, and Loewenstein 
2000), resulting in an improvement in their overall innovation performance. We expect firms with greater levels of technology area experience to obtain superior innovation performance in comparison to firms with less experience. We examine the following hypothesis:

Hypothesis 1a: Firms with greater technological area experience have higher rates of drug development success than firms with less experience. ceteris paribus

Hypothesis $1 \mathrm{~b}$ : Firms with greater technological area experience have lower rates of drug development termination than firms with less experience. ceteris paribus

\subsection{Technology experience diversity}

Experience diversity refers to the extent to which a firm's technology experience is diversified across different technology areas (Breschi, Lissoni, and Malerba 2003; Gambardella and Torrisi 1998). In the literature we find evidence that suggests that knowledge and technology development benefits from diversity due to economies of scope and KBV (Almeida and Phene 2004; Granstrand 1998). Technology experience diversity improves a firm's ability to develop innovative knowledge through the combination of various different technologies (Boh, Evaristo, and Ouderkirk 2014; Granstrand 1998). Other studies connect organisation survivability to their ability to develop diversified technology portfolios (Suzuki and Kodama 2004) or the diversity of their new technology areas searches (Jiang, Tan, and Thursby 2011). What these studies show is that having a diverse technology portfolio will allow firms to develop new knowledge from innovative breakthroughs due to their enhanced ability to draw from experiences across different areas of expertise. Also, having a larger stock of technology development capabilities allows firms to increase the possibility of creating new combinations leading to novel ideas (Fauconnier and Turner 1998) or more effective strategic alliances (Lin 2011). Another advantage of technology experience diversity is knowledge spillovers among different units leading to a more efficient knowledge development than those firms with less diversified experience (Almeida and Phene 2004; Laursen and Salter 2014).

Studies on team performance suggest that when a team involved in project development has highly diversified past experience it brings the product from concept to market more efficiently (Buyl et al. 2011; Clark and Fujimoto 1991; Faems and Subramanian 2013; Garvin 1988). This is because more heterogeneous past experience results in an increased ability to make good decisions regarding future research or development processes (Cohen and Levinthal 1990; Wei and Wu 2013) and because firms with less diversified experience risk entering competency traps that can result in delays in development. In other words, experience diversity helps overcome organisational inertia (Wang and Chen 2010). Organisations may become fixed in their way of interpreting tasks, and that as things change, the organisation will fail to respond adequately due to competency traps (Leonard-Barton 1992; Levitt and James 1988) and may end up using knowledge gained in the past even when it is not appropriate, thus resulting in negative performance. We discuss the following hypotheses.

\footnotetext{
Hypothesis 2a: Firms with greater technology experience diversity have higher rates of drug development success than firms with less experience diversity. ceteris paribus

Hypothesis 2b: Firms with greater technology experience diversity have lower rates of drug development termination than firms with less diversity. ceteris paribus
}

\subsection{Interaction between technology area experience and experience diversity}

The above discussion leads us to the conclusion that organisations can improve their innovation performance by means of their experience in a particular technological area and the diversity of their overall experience. Other studies in the areas of organisational learning (Wang and Chen 2010) and knowledge search (Laursen and Salter 2006) have also highlighted the importance of both elements in developing innovation capabilities An important question is whether these two aspects of an organisation's past experience are distinct, or whether they interact with each other; and if they interact, what sort of interaction exists between them. In this section, we argue that 
the full extent to which technology area experience and diversity affect performance depends on the interaction between these two factors. We maintain that they are at once conceptually different and narrowly interconnected and that one cannot be understood without the other if we really want to get a clear picture of how experience affects knowledge development.

The learning curve literature shows that organisations vary considerably in the rates at which their technology area experience affects performance. Equal increases of technology area experience might affect organisational performance differently. Past research has found that differences in development rates is a function not only of differences in the product, but also of differences in organisations. There is evidence to suggest that there is often more variation across organisations working on the same area than within an organisation producing different products (Argote, Beckman, and Epple 1990). For example, in shipbuilding during the Second World War, there was a greater variation in performance with the increase of technology area experience within production programmes than between programmes (Searle 1945). Factors found to condition such variation include the possibility of differences in organisational forgetting rates (Besanko et al. 2010) and employee turnover (Erden, von Krogh, and Nonaka 2008). Another factor connected to this variation is an organisation's ability to transfer knowledge from other areas of expertise within the same organisation (Argote, Beckman, and Epple 1990).

We argue that organisations with greater experience diversity have access to a greater range of knowledge (which can be transferred to a new area) than organisations with a more homogenous base. What we suggest here is that if two organisations have the same amount of technology area experience, but one of them has higher levels of experience diversity, the one with more diversity will have a richer variety of examples from which to draw knowledge for the task in question. In this respect, we expect experience diversity to help explain differences in the impact of technology area experience on innovation performance across organisations. Firms with equivalent levels of technology area experience but with different levels of experience diversity might have different rates of learning, resulting in variance in innovation performance.

Some sections of the literature suggest that high levels of technology area experience may increase the risk of an organisation's failure to appreciate the unique aspects of the project in question, as it may be 'blinded' by schemas transferred from similar projects (Baum and Ingram 1998; Kahneman 2003). In order to avoid falling into narrow framing, an organisation needs to keep a certain level of openness while increasing its experience in the task. Experience diversity may help keep a healthy level of vigilance in the organisation when dealing with highly familiar projects. Experience in dealing with a variety of tasks may prevent excessive technology area experience from leading to narrow framing and a decrease in performance. On the contrary, high levels of technology area experience in the presence of past experience diversity should allow an organisation to fully benefit from its expertise in the task. In addition, and in the context of external knowledge search, we find evidence that combining depth and breadth of knowledge can improve innovation performance (Laursen and Salter 2006). The above leads to the following two hypotheses:

Hypothesis 3a: The effect of technology area experience on rates of drug development success is positively moderated by firm's experience diversity. ceteris paribus

Hypothesis 3b: The effect of technology area experience on rates of drug development termination is negatively moderated by firm's experience diversity. ceteris paribus

\section{Methods}

\subsection{Research setting}

The pharmaceutical industry offers fertile ground for answering our research question. Efficiently responding to new advances and developments is crucial as companies face tremendous pressures to innovate. Given the low probability of a product reaching the market, ranging between $16 \%$ and 
Table 1. List of pharmaceutical and biotech companies in the data set.

\begin{tabular}{|c|c|c|}
\hline Company & Country & Total Revenues (USD millions) \\
\hline Pfizer & USA & 67,809 \\
\hline Novartis & Switzerland & 53,324 \\
\hline Merck \& Co & USA & 45,987 \\
\hline Bayer & Germany & 44,200 \\
\hline GlaxoSmithKline & UK & 42,813 \\
\hline Johnson and Johnson & USA & 37,020 \\
\hline Sanofi & France & 35,645 \\
\hline Hoffmann-La Roche & Switzerland & 33,547 \\
\hline AstraZeneca & UK & 26,475 \\
\hline Abbott Laboratories & USA & 22,476 \\
\hline Bristol-Myers Squibb & USA & 17,914 \\
\hline Eli Lilly and Company & USA & 15,691 \\
\hline Astellas & Japan & 14,268 \\
\hline Boehringer Ingelheim & Germany & 13,284 \\
\hline Schering-Plough & USA & 10,594 \\
\hline Wyeth & USA & 10,378 \\
\hline Takeda Pharmaceutical Co. & Japan & 10,284 \\
\hline Johnson \& Johnson & USA & 9284 \\
\hline Mitsubishi Tanabe Pharma & Japan & 8964 \\
\hline Nycomed Pharma & Switzerland & 7631 \\
\hline Daiichi Sankyo & Japan & 6298 \\
\hline Teva & Israel & 5798 \\
\hline Shionogi & Japan & 5298 \\
\hline Solvay & Belgium & 4798 \\
\hline Eisai & Japan & 4298 \\
\hline Dainippon Sumitomo Pharma & Japan & 3798 \\
\hline Servier & France & 3298 \\
\hline Kyowa Hakko Kirin & Japan & 2798 \\
\hline Mitsubishi Tanabe Pharma & Japan & 2298 \\
\hline Gedeon Richter & Hungary & 1798 \\
\hline
\end{tabular}

19\% (DiMasi et al. 2010) and the decline in R\&D productivity (Bradfield and El-Sayed 2009), a critical factor for managers is to allocate $R \& D$ resources wisely. In this context, leveraging past experience for drug development is of vital importance for the pharmaceutical industry, as it will inform decisions regarding costly project development.

\subsection{Sample and data}

In order to overcome a potential bias that could arise from using firms with few projects in their portfolio, we identified 30 global pharmaceutical and biotech companies with at least 24 projects in their portfolios (Table 1). We decided to limit the sample to firms with at least 24 projects in order to be able to explore changes in past experience diversity. Each firm in the sample has an average of 100 active projects over the study period (1980-2008), with some having as many as 400 . The diversity variable would lose its explanatory potential in cases where firms had been involved few projects in the past. This resulted in a sample of 3035 projects that were divided into three categories: terminated, approved and active. Of these 3035 projects, 348 were successfully launched, 2528 were ceased and 159 were still active by the end of the study period. The projects in the sample are also distributed across 17 different therapy areas. The starting dates of all the projects in this study range from 1980 to 2008 . We used 1980 as the starting point for the study period because it was the year in which the commercialisation of biotechnology occurred.

For all these firms we used Pharma Projects. Pharmaprojects is a Pharmaceutical Research and Development Pipeline Intelligence database. The database contains both published and unpublished information on pharmaceutical projects based on company questionnaires, Securities and Exchange Commission (SEC) and Food and Drug Administration (FDA) filings, journals, annual reports, industry conferences and press releases among others. Pharmaprojects staff attend international meetings to 
obtain information directly from research scientists. They also scan conference proceedings and the scientific and medical literature to track new products.

\subsection{Estimation procedure: competing risk}

We use competing risk analysis as the best possible method when the dependent variable combines the probability of, and the time to, a focal event. Drug development projects are at risk of being approved or terminated. Because both outcomes are mutually exclusive, we use competing risk to model them. Our model calculates the cumulative incidence rate of each project making the transition to either approved or terminated. This transition is captured by the instantaneous transition rate $r$, defined by

$$
r_{k}(t)=\lim _{\Delta t \rightarrow 0} \frac{\operatorname{Pr}(t \leq T<(t+\Delta t), D=k T \geq t)}{\Delta t},
$$

where $k$ represents one of the two possible outcomes in $D$. The variable $T$ measures the time spent at risk of making one of the two possible transitions during the time interval from $t$ to $(t+\Delta t)$, conditional on the project being at risk of making a transition at time $t$. This rate can be interpreted to mean that the variable of interest leads to a faster (slower) occurrence of the event. Higher (lower) incidence rates suggest a larger (smaller) number of such events within a given time period.

\subsection{Dependent variables}

Similar to previous work in the pharmaceutical industry (Cockburn and Henderson 2001; Danzon, Nicholson, and Pereira 2005; Macher and Boerner 2012) we explore drug development performance as an indicator of innovation performance. While these studies specify drug development performance as either drug development approval or drug development submission time, we employ competing analysis and understand performance as the combination of rates of development approval and rates of drug development termination. Our dependent variable not only takes into consideration those drugs development projects that are successful but also those that fail. By taking into account failure we acquire a more comprehensive understanding of innovation. The incidence rate for drug approval indicates the number of projects that are expected to be approved over the period of one day (as days are the time unit employed in this study). Similarly, the rate of drug termination indicates the number of projects that are expected to be terminated over the period of one day. As it is the norm with competing risk analyses we report the coefficients that correspond to the incidence rates.

\subsection{Independent variables}

\subsubsection{Technological area experience}

Drug development projects are divided into different technology areas via therapeutic areas. We employ this classification to create our technology area experience variable. Prior experience in a certain therapeutic area is vital when developing future similar drug developments. As this experience grows firms develop deep expertise in the therapeutic area in question. TA experience in this study is measured by:

$$
\text { TA experience }{ }_{i, j, t}=\frac{100 \times \text { time }_{i, j, t}}{\text { Time }_{i, t}},
$$

where time $e_{i, j}$ represents the total number of days that firm $i$ spent in therapeutic area $j$ at time $t$, and Time $_{i, j, t}$ represents the total number of days that firm $i$ spent across all therapeutic areas that it was 
engaged with at time $t$. This measure represents the level of familiarity that a firm would have with a given project's main therapy area in comparison to the firm's overall experience across all areas.

\subsubsection{Experience diversity}

In order to understand differences in firms' past experience, we use the entropy measure of diversity as it is defined in the diversification literature (Palepu 1985). The entropy measure compares very well with other measures of diversity (Amit and Livnat 1988; Farjoun 1998; Jacquemin and Berry 1979; Palepu 1985). The entropy measure only uses the time spent by firms in each therapy area in its computation. The less a firm's time is dispersed across different therapy groups, the higher the related component of the entropy measure is. We use the number and types of therapy codes in which firms have operated and the distribution of firms' time across these codes to create a measure of diversification. Let EMD be the entropy measure of diversification. This arises out of operating across several therapy areas. EMD is defined as

$$
\mathrm{EMD}=\sum_{j=1}^{M} P^{j} 1 n\left(\frac{1}{P^{j}}\right),
$$

where $P^{j}$ is the share of the $j$ th therapy area in the total time invested by the firm in all projects. Note that EMD is the weighted average of the diversification within all the $M$ therapy areas. Each therapy area receives a weightage equal to its share, which provides a measure of its importance within the total operations of the firm. This expression calculates the share of each therapy area in the total time invested by the firm in all areas.

\subsection{Control variables}

We include several control variables at the firm and drug level. Firm age and size affect rates of drug approval and termination. Younger firms might not benefit as much from their experience as older ones do, but older firms might become stagnant and inertial resulting in decreased performance (Carroll and Hannan 2004). Also larger firms might find it more difficult to adapt to changes in the industry due to higher levels of bureaucratisation than smaller firms. Originator captures 29 dummy variables, one for each firm in the sample, and controls for the above concerns and firmlevel heterogeneity. At the firm level we also look at the number of other projects active in the firm as this will affect to what extent a given project needs to compete for resources. We code this as pipeline density reflecting the level of competition for resources at the project level. This control variable indicates the number of projects active in a firm at any one time averaged by the number of other projects that the firm has developed to date. We average by the number of other projects that the firm has developed to date in order to make it proportional to the size of the firm. Similarly, we also control for the total number of other projects in the industry, as the probability that a project is approved or terminated might depend on the number of other projects seeking approval from the FDA. Furthermore, the information that firms gather from external projects might affect decisions regarding their own drug development projects.

We also include drug compound-related information in our analysis. Some drugs have more pharmacological indications than others. In projects with more indications, scientists are able to leverage knowledge more readily since many of the indications share biological processes and/or target molecules that are common across many indications. Thus, the organisation may obtain more useful information for testing new compounds from projects with a greater number of indications, which enhances project performance. We created pharmacology indications as a variable indicating the number of different pharmacological codes concerning each project. Some of the projects might have up to 20 pharmacology indications, while others only have 1 . At the compound level we also included therapeutic area. The characteristics of therapy areas to which a project belongs may affect the outcome of the project (Danzon, Nicholson, and Pereira 2005; Macher and Boerner 2006). 
We created 16 dummy variables that represent the main therapy area to which each project belongs. We also control for project governance. We created the variable solo to capture whether a project is conducted solo or in collaboration with another firm as it can affect the level of support for a project. We coded the governance type of each drug development project with ' 1 ' for solo projects and ' 0 ' for those conducted in collaboration with another firm. We would expect that solo projects would take longer to complete than those conducted in collaboration with another organisation. We also control for unobservable year effects and for right truncation with a dummy variable for the year the project was initiated. This variable accounts for the expectation that projects starting later in the study period are less likely to lead to approval (or termination) outcomes (Hoang and Rothaermel 2010).

\section{Results}

In Table 2, we present the descriptive statistics of the variables and bivariate correlation matrix. The average proportional hazard rate for project approval is .000022 . For terminating a project, the proportional hazard rate is .00015 . We observe a moderately high correlation between technology area experience and experience diversity $(-0.22, p<.001)$, which indicates that an increase in technology area experience is associated with a decrease in experience diversity. We also find that the correlation between project year and industry density is very high $(r=0.96, p<.001)$. One reason for the high correlation could be that the number of projects active in the industry has increased progressively over time. A reason for multicollinearity in time series data like the one employed in this work is that regressors included in the model share a common trend, that is, they all increase or decrease over time.

Thus, the high degree of correlation between project year and industry density may be due to both growing at more or less the same rate (Gujarati 1988).

In Table 3, we present the results predicting project performance. Model 1 (drug approval) and Model 2 (drug termination) include the baseline estimations containing project-level and firm-level controls. In Model 3 (drug approval) and Model 4 (drug termination), we entered the explanatory variables of technology area experience and diversity and in order to test for Hypotheses $1 \mathrm{a}, 1 \mathrm{~b}, 2 \mathrm{a}, 2 \mathrm{~b}$. In Models 5 and 6, we added a two-way interaction effect that allows us to test Hypotheses 3a and 3b.

In Hypothesis 1a, we suggest that an increase in technology area experience will result in an increase in the rate of project success. Contrary to what we state in our hypotheses the results in Models 3 suggest that task experience negatively affects the rate for drug approval. The above rules out what was suggested in Hypothesis $1 \mathrm{a}$. In Hypothesis $1 \mathrm{~b}$, we predicted the relationship between technology area experience and the probability of drug development project termination to be negative. Our findings do not support this hypothesis. The results in Model 4 suggest that technology area experience is positive and significant. This indicates that an increase in area technology experience would increase the incidence rate for drug termination.

In Hypothesis 2a, we suggest that the relationship between experience diversity and the probability of drug development project success is positive. In model 3 the linear term is both positive and significant, which indicates that as diversity increases the incidence rate for approval increases. These findings support our hypothesis. In Hypothesis $2 \mathrm{~b}$, we stated that the relationship between experience diversity and the probability for drug development termination is positive. In model 4, the linear term for experience diversity is negative and significant, which indicates that as firms increase their experience diversity their rate of drug development termination decreases. This finding also supports our hypothesis.

In Hypothesis 3a, we suggest that the effect of technology area experience on rates of drug development success is moderated by firm's experience diversity. Results in model 5 suggest that high levels of experience diversity and technology area experience have a positive impact on performance by increasing the incidence rate for project success. This finding supports Hypothesis 3a. With respect to Hypothesis $3 \mathrm{~b}$, our results show that high levels of technology area experience in the presence of high experience diversity has a negative impact on the rate of project termination (model 6). 
Table 2. Descriptive statistics and bivariate correlation matrix.

\begin{tabular}{|c|c|c|c|c|c|c|c|c|c|c|c|}
\hline & Mean & Std. Dev. & Min & Max & 1 & 2 & 3 & 4 & 5 & 6 & 7 \\
\hline 1. Pharmacology indications & 1.489292 & 1.02834 & 1 & 20 & 1 & & & & & & \\
\hline 2. Project governance & 0.8537068 & 0.353458 & 0 & 1 & -0.2401 & 1 & & & & & \\
\hline 3. Project year & 06-Jul-87 & 4.56 & 05-Jan-80 & 30-Dec-94 & 0.0046 & 0.0581 & 1 & & & & \\
\hline 4. Pipeline density & 88.17265 & 88.01513 & 0 & 421 & -0.059 & 0.0984 & 0.5199 & 1 & & & \\
\hline 5. Industry density & 1458.86 & 804.9905 & 0 & 2702 & 0.0087 & 0.0554 & 0.9962 & 0.5214 & 1 & & \\
\hline 6. Experience diversity & 0 & 0.174878 & -1.0718 & 0.3029456 & -0.0109 & 0.0025 & 0.0311 & 0.2486 & 0.0245 & 1 & \\
\hline 7. Technological area experience & 0 & 0.084553 & -0.12868 & 0.439099 & -0.058 & 0.0544 & -0.0211 & -0.0159 & -0.0216 & -0.221 & 1 \\
\hline
\end{tabular}

Notes: $N=3034$. Bold indicates pair-wise correlation significance at 0.05 level. 
Table 3. Results predicting drug approval and drug termination.

\begin{tabular}{|c|c|c|c|c|c|c|}
\hline & $\begin{array}{c}\text { Model } 1 \\
\text { Drug approval }\end{array}$ & $\begin{array}{c}\text { Model } 2 \\
\text { Drug termination }\end{array}$ & $\begin{array}{c}\text { Model } 3 \\
\text { Drug approval }\end{array}$ & $\begin{array}{c}\text { Model } 4 \\
\text { Drug termination }\end{array}$ & $\begin{array}{c}\text { Model } 5 \\
\text { Drug approval }\end{array}$ & $\begin{array}{c}\text { Model } 6 \\
\text { Drug termination }\end{array}$ \\
\hline Therapeutic area & Included & Included & Included & Included & Included & Included \\
\hline Originator & Included & Included & Included & Included & Included & Included \\
\hline \multirow[t]{2}{*}{ Pharmacology indic. } & $.22498569^{* * *}$ & $-.5190908^{* * *}$ & $.19772511^{* * *}$ & $-.49715294^{* * *}$ & $.20084038^{* * *}$ & $-.49622625^{* * *}$ \\
\hline & 0.03505008 & 0.04694727 & 0.03486826 & 0.04894738 & 0.03576313 & 0.04889022 \\
\hline \multirow[t]{2}{*}{ Project governance } & $-2.2060261^{* * *}$ & $2.193808 * * *$ & $-1.8793259^{* * *}$ & $2.1037333 * * *$ & $-1.8738138^{* * *}$ & $2.1061251^{* * *}$ \\
\hline & 0.14000148 & 0.12464794 & 0.14082475 & 0.14148698 & 0.13923479 & 0.14133402 \\
\hline \multirow[t]{2}{*}{ Project year } & $-.00166941^{* * *}$ & $.0010114^{* * *}$ & $-.00157561^{* * *}$ & $.00111995^{* * *}$ & $-.00151281 * * *$ & $.00109859 * * *$ \\
\hline & 0.0003936 & 0.00017425 & 0.00039379 & 0.00017322 & 0.00039602 & 0.00017301 \\
\hline \multirow[t]{2}{*}{ Pipeline density } & 0.00120478 & -0.00025713 & 0.00163911 & $-.00253645^{* * *}$ & 0.0020721 & $-.00259506^{* * *}$ \\
\hline & 0.00209148 & 0.00053828 & 0.00207077 & 0.00054882 & 0.00209796 & 0.00056228 \\
\hline \multirow[t]{2}{*}{ Industry density } & $.00311051^{* * *}$ & $-.00097802^{* *}$ & $.00287279 * * *$ & $-.00073507^{*}$ & $.00270282 * * *$ & -0.00067789 \\
\hline & 0.00079309 & 0.00036109 & 0.00078801 & 0.00035219 & 0.00079572 & 0.00035122 \\
\hline \multirow[t]{2}{*}{ Experience diversity } & & & $27.765973 * * *$ & $-21.467324 * * *$ & $31.906205^{* * *}$ & $-22.127265^{* * *}$ \\
\hline & & & 6.0677292 & 1.2564302 & 6.4788208 & 1.2908379 \\
\hline \multirow[t]{2}{*}{ Technological area experience } & & & $-2.5099478^{*}$ & $2.0175919^{* * *}$ & -1.2618811 & 0.33435193 \\
\hline & & & 1.2120301 & 0.43318609 & 1.3442073 & 0.59207944 \\
\hline \multirow[t]{2}{*}{ Exp. diver. $\times$ techn area exp } & & & & & $15.911276^{* * *}$ & $-5.2839825^{* * *}$ \\
\hline & & & & & 4.1179251 & 1.3090883 \\
\hline Wald Chi square & $863.98^{* * *}$ & $1520.54 * * *$ & $904.91 * * *$ & $1649.85^{* * *}$ & $900.17^{* * *}$ & $1693.26^{* * *}$ \\
\hline Log pseudolikelihood & -2339.7694 & -17022.103 & -2312.9529 & -16614.897 & -2305.3612 & -16601.104 \\
\hline
\end{tabular}

Note: $N=3034$.

$+p<0.1$.

${ }^{*} p<.05$.

${ }^{* *} p<.01$.

$* * *<.001$ 


\section{Discussion}

Our findings support the assumption that more experience is always beneficial as enhances learningby-doing and decision-making (Grant 1996), economies of scale (McDonald, Westphal, and Graebner 2008) or expertise (Leonard-Barton 1992). Even though our findings support the above assumption, they also qualify how this assumption should be understood.

First, and contrary to what other studies suggest (Macher and Boerner 2012), our findings indicate that the relationship between technology area experience is not unambiguously positively correlated with performance. Our results show that as technology area experience increases, the rate at which projects are approved diminishes, while the rate at which projects are terminated increases. This suggests that high levels of technology area experience can prevent a firm from making the appropriate inferences from what has been learnt. These findings are in line with some other findings in the literature suggesting that high levels of technology area experience could lead to a decrease in performance due to narrow framing (Kahneman 2003). The rationale maintains that high levels of technology area experience could lead to inadequate framing of new projects and therefore result in negative knowledge transfer that can affect the firm's ability to commercialise new knowledge. We understand that a high level of technology area experience can be a consequence of a mostly exploitative strategy. Exploitation favours engagement in $\mathrm{n}$ areas in which the organisation is already experienced (March 1991). As consequence our findings could also be interpreted as suggesting a negative relationship between exploitation and performance.

Our findings that diverse experience leads to superior performance support other works in the field. In particular, they are in line with other work on project development that suggests diversification helps innovation performance (Clark and Fujimoto 1991; Garvin 1988; Melero and Palomeras 2014; Østergaard, Timmermans, and Kristinsson 2011). Experience diversity, as suggested in this article, allows a firm to keep the sense of a situation open; this is certainly an advantage in the context innovation in the pharmaceutical industry, in which managers and scientists are constantly facing novel problematic situations. Even though our findings support the idea that diversity leads to openness when dealing with novel problems (Cohen and Levinthal 1990), we also acknowledge that achieving diversity of experiences might be negatively affected by factors like an overly strong emphasis on appropriability (Laursen and Salter 2014). As argued with technology area experience, we suggest that our findings also have implications for research on exploration and exploitation. A diverse experience can be seen as a consequence of explorative strategies, which would suggest that our findings indicate a positive relationship between exploration and performance.

A crucial outcome of this paper relates to findings in the literature suggesting that there is often more variation across organisations working on the same technology area than within an organisation producing different products (Argote, Beckman, and Epple 1990). Our findings suggest that one factor that explains why the same level of technology area experience might lead to differences in performance reflects variation in experience diversity. As a result we maintain with other studies in the field that technology area experience and experience diversity are narrowly connected and need to be studied together in order to really understand what effect experience has on innovation (Boh, Evaristo, and Ouderkirk 2014; Laursen and Salter 2006). In particular, our findings support other studies that maintain that achieving depth and breadth of knowledge enhances innovation performance (Laursen and Salter 2006). The results of our study show that when an increase in diversity is accompanied by an increase in technology area experience, the firm will benefit from an increase in the rate at which projects are approved. This suggests that the negative impact on the rate of drug approval that we found was associated with increases in technology area experience will vanish when combined with an increase in diversity. This supports the idea that technology area is only damaging to a firm's innovation performance when the firm has a limited variety of knowledge that it can refer to when working on new projects'. In other words, real damage to innovation performance does not result from technology area experience itself, but from high levels of technology area in the absence of expertise in other areas. An increase in technology area experience is not harmful if a firm combines it with experience in other 
areas. The danger of narrow framing posed by high levels of technology area experience vanishes when a firm has been exposed to a variety of other areas.

This work has certain limitations. First, we conduct our research in single industry. This is a limitation for the generalisation of our findings. A more complete picture would consider other industries. Second, further research in the area may wish to consider conceptualising technology area experience and experience diversity differently. Although we employ well-established and tested measurements, it would beneficial for the generalisation of findings to explore how other measurements of the explanatory variables compare to the ones employed here. Third, due to data limitations, we examine only drug compounds developed by 30 large pharmaceutical companies. Even though our sample is large enough to yield valid results, it would be more informative if we could conduct the same study on a larger and more diverse firm sample. Fourth, drivers of innovation are various and our study does not directly addresses factors like non R\&D variables (HervasOliver, Garrigos, and Gil-Pechuan 2011) or the acquisition of new equipment (Hervas-Oliver, Sempere-Ripoll, and Boronat-Moll 2014) that have been proven to be relevant in this context.

\section{Conclusion}

This essay elucidates how experience explains difference in innovation capabilities within and between firms. Several contributions at the theoretical level to existing KBV research are proposed. We find that both technology area experience and experience diversity have performance implications, which adds to the KBV research that examines boundary decisions. Both, technology area experience and experience diversity are found to have important performance effects. Technological area experience facilitates knowledge development through experiential learning-by-doing and experience diversity through spillovers. Furthermore, we suggest that firms can only fully realise the potential of their technology area experience when combined with a wide enough base of experience diversity. If technology area experience is not accompanied by experience diversity then firms are at risk of incurring negative knowledge transfer and narrow framing. We, therefore, argue that technology area experience and experience diversity are important and interdependent determinants of firms' ability to correctly leverage their experience for better innovation. We also suggest that both have to be considered jointly when researching the relationship between experience and innovation performance. The importance of experience diversity that this study highlights might also be behind the motivation for companies to enter into mergers and acquisitions; companies can expand the diversity of experiences by getting access to the experiences of other companies in the industry. In this respect, acquiring or merging with another company is a way of widening the experience pool of a company and by extension increasing its innovation performance.

Also future research may consider disassociating between technology area experience and experience diversity, as one of our conclusions shows that one cannot be understood without the other. We believe that any future work that does not include both these ideas will risk obtaining spurious results. As we show in this essay, looking at only one of these variables can lead to misleading or incomplete results.

\section{Notes on contributors}

Antonio Garzón-Vico holds a Ph.D. in Management and an Mlitt in Philosophy from University College Dublin and a Degree in Philosophy from 'Universidad de Granada'. Antonio is a postdoc researcher in the Chair of Business of Biotech in University College Dublin. During his Ph.D. studies Antonio obtained the Best Paper Award from the Academy of Management Conference in 2012, published academic articles in peer reviewed journals and presented at various international conferences. While completing his Ph.D. Antonio also worked as Programme Manager in the Overseas Programmes in UCD School of Business. His current research interests revolve around organisational learning (learning from failure and success) and CEO's role in innovation in the Biotech Industry.

Professor Patrick Gibbons was appointed Jefferson Smurfit Professor of Strategic Management in 2003. He graduated with a Ph.D. in Strategic Planning and Policy from the University of Pittsburgh. Prior educational qualifications at 
Bachelor's and Master's levels were gained at UCD. Before entering academia, he worked in a number of financial and corporate strategy roles with KPMG, Jefferson Smurfit Group, The Investment Bank of Ireland and An Post (The Irish Post Office). He also held the position of Vice President of Staff and Administrative Systems at UCD. His previous academic positions were held at the University of Pittsburgh, Nanyang University, Singapore and the Pennsylvania State University. His current research interests revolve around control practices of MNCs, the impact of strategic planning systems on organisational behaviour and performance, and the application of social theory to strategic process research.

Peter Mc Namara is the Professor of Management at Maynooth University (National University of Ireland Maynooth) and Head of the School of Business. He is currently the Program Chair of the Management Education and Development division of the Academy of Management (the AOM being an academic management professional organisation of circa 18,000 members). His previous academic appointments include being a tenured senior lecturer at University College Dublin, Michael Smurfit Graduate School of Business, and a Research Fellow at the Cass Business School, City University, London. Peter's research lies at the intersection of strategy, innovation and entrepreneurship. His work focuses primarily on two areas. First, he explores the process and performance consequences of collaboration within and between organisations. Second, he explores the process and performance consequences of innovation in terms of science, knowledge work, and business processes. His work focuses on strategic issues relating to business model design and innovation; capturing financial value from innovation and R\&D; inter-organisational collaboration processes and performance; and the micro foundations of competitive advantage.

Professor Rosier holds both a Ph.D. in Pharmaceutical Sciences (Ghent University, Belgium) and a Ph.D. in Management (Cranfield School of Management, UK). He was a Fulbright Scholar at the Harvard School of Public Health and was awarded a NATO research fellowship for research at MIT. As vice president pharmaceutical drug development at Johnson \& Johnson he was instrumental in the development of TIBOZOLE ${ }^{\circledR}$, LIVOSTIN ${ }^{\circledR}$, PREPULSID $^{\circledR}$, SPORANOX $^{\circledR}$, RISPER- $^{\circ}$ $\mathrm{DAL}^{\circledR}$ and ERGAMISOL ${ }^{\circledR}$ and was awarded the Johnson \& Johnson Leadership Award for outstanding and exceptional contribution to the development of PREZISTA ${ }^{\circledR}$ and INTELENCE ${ }^{\circledR}$ for the treatment of AIDS. In 2009, he became Chief Executive Officer of FORMAC Pharmaceuticals NV, a high technology drug delivery spin-off from the University of Leuven that uses silica-based technology to increase the performance of drugs. Jan has extensive experience in attracting venture capital for high-risk academic spin-off biotech firms. His career has continuously taken place at the interface between university and industry. During his stay in industry he was engaged in academic biomedical research which resulted in scientific papers published in e.g. the International Journal of Pharmaceutics, European Journal of Biopharmaceutics, Electrophoresis, Journal of Chromatography Biomedical Applications, Nature, etc. Since 2008, he teaches new drug development at the University of Leuven as a visiting professor. He also researches innovation in biotech firms as a Visiting Fellow at the Cranfield School of Management (UK). Jan is author of Global New Drug Development - An Introduction (Wiley-Blackwell) and is currently writing his new book on the business of biotechnology. He is also a member of the Advisory Board of Incentives for Global Health's Health Impact Fund (healthimpactfund.org).

\section{References}

Almeida, P., and A. Phene. 2004. "Subsidiaries and Knowledge Creation: The Influence of the MNC and Host Country on Innovation." Strategic Management Journal 25 (8-9): 847-864.

Amit, R., and J. Livnat. 1988. "Diversification Strategies, Business Cycles and Economic Performance." Strategic Management Journal 9 (2): 99-110.

Argote, L., S. L. Beckman, and D. Epple. 1990. "The Persistence and Transfer of Learning in Industrial Settings." Management Science 36 (2): 140-154.

Argote, L., and Y. Ren. 2012. "Transactive Memory Systems: A Microfoundation of Dynamic Capabilities." Journal of Management Studies 49 (8): 1375-1382.

Baum, J., and P. Ingram. 1998. "Survival Enhancing Learning in the Mahattan Hotel Industry, 1998-1980." Management Science 44 (7): 996-1016.

Besanko, D., U. Doraszelski, Y. Kryukov, and M. Satterthwaite. 2010. "Learning-by-Doing, Organizational Forgetting, and Industry Dynamics." Econometrica 78 (2): 453-508.

Boh, W. F., R. Evaristo, and A. Ouderkirk. 2014. "Balancing Breadth and Depth of Expertise for Innovation: A 3M Story." Research Policy 43 (2): 349-366.

Bradfield, R., and H. El-Sayed. 2009. "Four Scenarios for the Future of the Pharmaceutical Industry." Technology Analysis \& Strategic Management 21 (2): 195-212.

Breschi, S., F. Lissoni, and F. Malerba. 2003. "Knowledge-relatedness in Firm Technological Diversification." Research Policy 32 (1): 69-87.

Buyl, T., C. Boone, W. Hendriks, and P. Matthyssens. 2011. "Top Management Team Functional Diversity and Firm Performance: The Moderating Role of CEO Characteristics." Journal of Management Studies 48 (1): 151-177.

Carroll, G. R., and M. T. Hannan. 2004. The Demography of Corporations and Industries. Princeton, NJ: Woodstock: Princeton University Press.

Clark, K. B., and T. Fujimoto. 1991. Product Development Performance : Strategy, Organization, and Management in the World Auto Industry. Boston, MA: Harvard Business School Press. 
Cockburn, I. M., and R. M. Henderson. 2001. "Scale and Scope in Drug Development: Unpacking the Advantages of Size in Pharmaceutical Research." Journal of Health Economics 20 (6): 1033-1057.

Cohen, W. M., and D. A. Levinthal. 1990. "Absorptive Capacity: A New Perspective on Learning and Innovation." Administrative Science Quarterly 35 (1): 128-152.

Danzon, P. M., S. Nicholson, and N. S. Pereira. 2005. "Productivity in Pharmaceutical-biotechnology R\&D: The Role of Experience and \$lliances." Journal of health economics 24 (2): 317-339.

DiMasi, J. A., L. Feldman, A. Seckler, and A. Wilson. 2010. "Trends in Risks Associated With New Drug Development: Success Rates for Investigational Drugs." Clinical Pharmacology \& Therapeutics 87 (3): 272-277.

Erden, Z., G. von Krogh, and I. Nonaka. 2008. "The Quality of Group Tacit Knowledge." The Journal of Strategic Information Systems 17 (1): 4-18.

Ericsson, K. A., and N. Charness. 1994. "Expert Performance - Its Structure and Acquisition." American Psychologist 49 (8): 725-747.

Ernst, H., U. Lichtenthaler, and C. Vogt. 2011. "The Impact of Accumulating and Reactivating Technological Experience on R\&D Alliance Performance." Journal of Management Studies 48 (6): 1194-1216.

Faems, D., and A. M. Subramanian. 2013. "R\&D Manpower and Technological Performance: The Impact of Demographic and Task-related Diversity." Research Policy 42 (9): 1624-1633.

Farjoun, M. 1998. "The Independent and Joint Effects of the Skill and Physical Bases of Relatedness in Diversification." Strategic Management 19: 611-630.

Fauconnier, G., and M. Turner. 1998. "Conceptual Integration Networks." Cognitive Science 22 (2): 133-187.

Gambardella, A., and S. Torrisi. 1998. "Does Technological Convergence Imply Convergence in Markets? Evidence from the Electronics Industry." Research Policy 27 (5): 445-463.

Garnier, J.-P. 2008. "Rebuilding the R\&D ENGINE in Big Pharma." Harvard Business Review 86 (5): 68-76.

Garvin, D. A. 1988. Managing Quality: The Strategic and Competitive Edge. New York: Free Press; Collier Macmillan.

Gino, F., L. Argote, E. Miron-Spektor, and G. Todorova. 2010. "First, Get Your Feet Wet: The Effects of Learning from Direct and Indirect Experience on Team Creativity." Organizational Behavior and Human Decision Processes 111 (2): $102-115$.

Granstrand, O. 1998. "Towards a Theory of the Technology-based firm." Research Policy 27 (5): 465-489.

Grant, R. M. 1996. "Toward a Knowledge-based Theory of the Firm." Strategic Management Journal 17: 109-122.

Gujarati, D. N. 1988. Basic Econometrics. New York, NY [u.a.]: McGraw-Hill.

Haleblian, J., and S. Finkelstein. 1999. "The Influence of Organizational Acquisition Experience on Acquisition Performance: A Behavioral Learning Perspective." Administrative Science Quarterly 44: 29-56.

Hervas-Oliver, J.-L., J. A. Garrigos, and I. Gil-Pechuan. 2011. "Making sense of Innovation by R\&D and Non-R\&D Innovators in Low Technology Contexts: A Forgotten Lesson for Policymakers." Technovation 31 (9): 427-446.

Hervas-Oliver, J.-L., F. Sempere-Ripoll, and C. Boronat-Moll. (2014). "Process Innovation Strategy in SMEs, Organizational Innovation and Performance: A Misleading Debate?" Small Business Economics 43 (4): 873-886.

Hoang, H., and F. T. Rothaermel. 2010. "Leveraging Internal and External Experience: Exploration, Exploitation, and R\&D Project Performance." Strategic Management Journal 31 (7): 734-758.

Jacquemin, A. P., and C. H. Berry. 1979. "Entropy Measure of Diversification and Corporate Growth." The Journal of Industrial Economics 27 (4): 359-369.

Jiang, L., J. Tan, and M. Thursby. 2011. "Incumbent firm Invention in Emerging Fields: Evidence from the Semiconductor Industry." Strategic Management Journal 32 (1): 55-75.

Kahneman, D. 2003. "Experiences of Collaborative Research." American Psychologist 58 (9): 723-730.

Kaitin, K., and J. DiMasi. 2011. "Pharmaceutical Innovation in the 21st Century: New Drug Approvals in the First Decade, 2000-2009." Clinical Pharmacology \& Therapeutics 89 (2): 183-188.

Laursen, K., and A. Salter. 2006. "Open for Innovation: The Role of Openness in Explaining Innovation Performance among UK Manufacturing Firms." Strategic management journal 27 (2): 131-150.

Laursen, K., and A. J. Salter. 2014. "The Paradox of Openness: Appropriability, External Search and Collaboration." Research Policy 43 (5): 867-878.

Leonard-Barton, D. 1992. "Core capabilities and Core Rigidities: A Paradox in Managing New Product Development." Strategic Management Journal 13 (S1): 111-125.

Lettl, C., K. Rost, and I. von Wartburg. 2009. "Why are Some Independent Inventors 'Heroes' and Others 'Hobbyists'? The Moderating Role of Technological Diversity and Specialization." Research Policy 38 (2): 243-254.

Levitt, B., and G. James. 1988. "Organizational Learning." Annual Review of Sociology 14: 319-338, March.

Lin, B.-W. 2011. "Knowledge Diversity as a Moderator: Inter-firm Relationships, R\&D Investment and Absorptive Capacity." Technology Analysis \& Strategic Management 23 (3): 331-343.

Macher, J. T., and C. Boerner. 2012. "Technological Development at the Boundaries of the Firm: A Knowledge-based Examination in Drug Development." Strategic Management Journal 33 (9): 1016-1036.

Macher, J. T., and C. S. Boerner. 2006. "Experience and Scale and Scope Economies: Trade-offs and Performance in Development." Strategic Management Journal 27 (9): 845-865.

Madsen, P. M., and V. Desai. 2010. "Failing to Learn? The Effects of Failure and Success on Organizational Learning in the Global Orbital Launch Vehicle Industry." Academy of Management Journal 53 (3): 451-476.

March, J. G. 1991. “Exploration and Exploitation in Organizational Learning." Organization Science 2 (1): $71-87$. 
McDonald, M. L., J. D. Westphal, and M. E. Graebner. 2008. "What Do They Know? The Effects of Outside Director Acquisition Experience on Firm Acquisition Performance." Strategic Management Journal 29: 1155-1177.

Melero, E., and N. Palomeras. 2014. "The Renaissance Man is not Dead! The Role of Generalists in Teams of Inventors." Research Policy 1 (2): 123-137.

Muehlfeld, K., P. Rao Sahib, and A. Van Witteloostuijn. 2012. "A Contextual Theory of Organizational Learning from Failures and Successes: A Study of Acquisition Completion in the Global Newspaper Industry, 1981-2008." Strategic Management Journal 33 (8): 938-964.

Nickerson, J. A., and T. R. Zenger. 2004. "A Knowledge-based Theory of the Firm - The Problem-Solving Perspective." Organization Science 15 (6): 617-632.

Østergaard, C. R., B. Timmermans, and K. Kristinsson. 2011. “Does a Different View Create Something New? The Effect of Employee Diversity on Innovation." Research Policy 40 (3): 500-509.

Palepu, K. 1985. "Diversification Strategy, Profit Performance and the Entropy Measure." Strategic Management Journal 6 (3): 239-255.

Reuer, J., M. Zollo, and H. Singh. 2002. "Post Formation Dynamics in Strategic Alliances." Strategic Management Journal 23 (2): 135-151.

Schilling, M. A., P. Vidal, R. E. Ployhart, and A. Marangoni. 2003. "Learning by Doing Something Else: Variation, Relatedness, and the Learning Curve." Management Science 49 (1): 39-56.

Searle, A. D. 1945. "Productivity of Labor and Industry." Monthly Labor Review 61 (6): 1132-1147.

Souitaris, V. 2002. "Technological Trajectories as Moderators of Firm-level Determinants of Innovation." Research Policy 31 (6): 877-898.

Spender, J. C. 1996. "Making Knowledge the Basis of a Dynamic Theory of the Firm." Strategic Management Journal 17: 45-62.

Su, P., and P. McNamara. 2012. "Exploration and Exploitation within and across Intra-organisational Domains and Their Reactions to Firm-level Failure." Technology Analysis \& Strategic Management 24 (2): 129-149.

Suzuki, J., and F. Kodama. 2004. "Technological Diversity of Persistent Innovators in Japan: Two Case Studies of Large Japanese Firms." Research Policy 33 (3): 531-549.

Thompson, L., D. Gentner, and J. Loewenstein. 2000. "Avoiding Missed Opportunities in Managerial Life: Analogical Training More Powerful Than Individual Case Training." Organizational Behavior and Human Decision Processes 82 (1): 60-75.

Vega-Jurado, J., A. Gutiérrez-Gracia, I. Fernández-de-Lucio, and L. Manjarrés-Henríquez. 2008. "The Effect of External and Internal Factors on Firms' Product Innovation." Research policy 37 (4): 616-632.

Wang, H., and W.-R. Chen. 2010. "Is Firm-specific Innovation Associated with Greater Value Appropriation? The Roles of Environmental Dynamism and Technological Diversity." Research Policy 39 (1): 141-154.

Wei, L.-Q., and L. Wu. 2013. "What a Diverse Top Management Team Means: Testing an Integrated Model." Journal of Management Studies 50 (3): 389-412.

Xu, S. 2015. "Balancing the Two Knowledge Dimensions in Innovation Efforts: An Empirical Examination among Pharmaceutical Firms." Journal of Product Innovation Management 32 (4): 610-621. 